JPE 11-1-1

\title{
A Fully Soft Switched Two Quadrant Bidirectional Soft Switching Converter for Ultra Capacitor Interface Circuits
}

\author{
Amin Mirzaei ${ }^{\dagger}$, Hosein Farzanehfard*, Ehsan Adib*, Awang Jusoh**, and Zainal Salam** \\ $\dagger * *$ Dept. of Electrical Eng., Universiti Teknologi Malaysia, Johor Bahru, Malaysia \\ * Dept of Electrical and computer Eng., Isfahan University of Technology, Isfahan, Iran
}

\begin{abstract}
This paper describes a two quadrant bidirectional soft switching converter for ultra capacitor interface circuits. The total efficiency of the energy storage system in terms of size and cost can be increased by a combination of batteries and ultra capacitors. The required system energy is provided by a battery, while an ultra capacitor is used at high load power pulses. The ultra capacitor voltage changes during charge and discharge modes, therefore an interface circuit is required between the ultra capacitor and the battery. This interface circuit must have good efficiency while providing bidirectional power conversion to capture energy from regenerative braking, downhill driving and the protecting ultra capacitor from immediate discharge. In this paper a fully soft switched two quadrant bidirectional soft switching converter for ultra capacitor interface circuits is introduced and the elements of the converter are reduced considerably. In this paper, zero voltage transient (ZVT) and zero current transient (ZCT) techniques are applied to increase efficiency. The proposed converter acts as a ZCT Buck to charge the ultra capacitor. On the other hand, it acts as a ZVT Boost to discharge the ultra capacitor. A laboratory prototype converter is designed and realized for hybrid vehicle applications. The experimental results presented confirm the theoretical and simulation results.
\end{abstract}

Key Words: DC-DC converter, Ultra capacitor (UC) zero current transition (ZCT), Zero voltage transition (ZVT)

\section{INTRODUCTION}

Traditionally, using a bidirectional DC/DC converter in conjunction with a low-voltage energy storage system has been a prominent option for hybrid electric and electric vehicles (HEV/EV). A battery is capable of storing large amounts of energy but is not suitable for supplying a large amount of power in a very short time. An increase in efficiency can be achieved by combining a smaller battery with an ultracapacitor (UC). The former has a lower peak output power but the UC has the ability to supply a large burst of power. Typically, a battery is used to supply a large amount of power at light loads, thereby increasing the total efficiency, whereas an UC bank is used for satisfying acceleration and regenerative braking requirements. This in turn improves the onboard battery life expectancy. An UC and a battery can be combined easily to meet the storage and peak current characteristics of EV [1]-[5], [16]. Furthermore this combination reduces the weight and size of the overall energy supply system.

[6] and [7] demonstrate the use of a cascaded bidirectional Buck-Boost converter used in a dc-motor-driven EV. The dc-

Manuscript received Oct. 13, 2009; revised Sep. 12, 2010

$\dagger$ Corresponding Author: mirzaee_amin@yahoo.com

Tel: +60-12-721-4787, Universiti Teknologi Malaysia

* Dept. of Electrical and computer Eng., Isfahan University of Technology, Iran

** Dept. of Electrical Eng., Universiti Teknologi Malaysia, Malaysia dc converters can be categorized into hard switching and softswitching converters. Due to the limited efficiency of hardswitching converters, soft-switching techniques are gaining popularity. Soft switching includes zero voltage switching (ZVS) and zero current switching (ZCS). Various soft switching techniques for increasing total efficiency are described elsewhere [8]-[22], [24].

In [16] a converter with parallel channels for a system based on a battery and an UC is described. [17] provides a ride-through with Flyback converter modules powered by an UC. The proposed approach is modular and allows for additional modules to be added to suit higher voltage/power ratings. In [18], a power-electronic interface for an UC-storage based substation in a DC-transportation networks is proposed. [19] describes the design of a high efficiency converter which allows for bidirectional energy flow under the softcommutation condition. [20] proposes a full-bridge/push-pull circuit-based bidirectional DC-DC converter which performs adequate charge and discharge operations between a lowvoltage high-current UC and a high-voltage low-current main battery.

Ultra capacitor voltage changes during the charge and discharge modes. Therefore an interface circuit is required between the ultra capacitor and the battery. This interface circuit should handle power flows from low voltage (LV) 


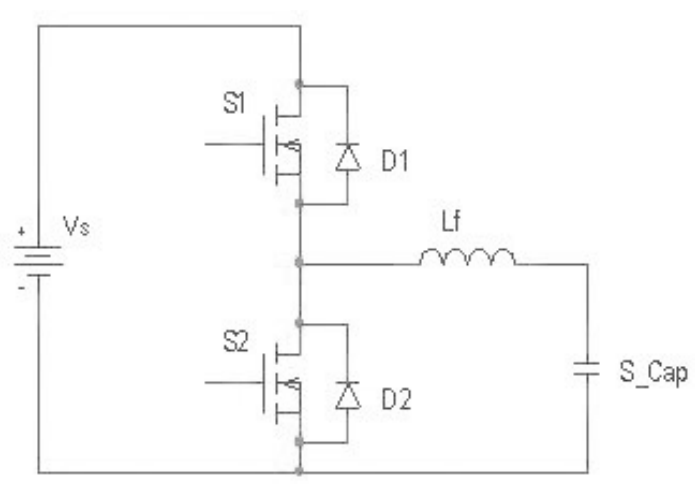

Fig. 1. Buck-Boost bidirectional dc-dc converter.

to high voltage (HV) and vice versa. A suitable topology for power flows from $\mathrm{LV}$ to $\mathrm{HV}$ is a Boost converter while power flows from $\mathrm{HV}$ to $\mathrm{LV}$ require a Buck converter. To achieve bidirectional capability, a Buck and Boost converter were combined and the resulting topology is shown in Fig. 1 [23].

In this paper, a modification of this topology is proposed. Both ZVS and ZCS techniques are applied to increase the efficiency of a bidirectional dc-dc converter. The proposed converter acts as a ZCT Buck to charge an ultra capacitor. On the other hand, it acts as a ZVT Boost to discharge an ultra capacitor. Efficiency, weight and cost are the three main parameters for the designing of converters in EV. Many articles have been written about interface circuits. Most of them applied soft switching techniques to increase efficiency, but they used many elements to achieve their aims, so their control systems were complex and they could not increase the efficiency as they wished. Meanwhile the weight and the initial cost of the interface circuit increased remarkably. In this paper, a fully soft switched two quadrant bidirectional soft switching converter is developed for UC interface circuits and it uses the minimum number of components to achieve the soft switching techniques and to increase efficiency. The proposed auxiliary circuit consists of two switches, one diode, two resonant inductors and one resonant capacitor. Moreover several ZVT converters and ZCT converters have been proposed but they suffer from one or more drawbacks such as: the auxiliary switch has a hard turn off which limits the gain in efficiency, the conduction losses are vastly increased, the high current peak is applied on the main switch, the switches have a hard turn off, and the main switch has a hard turn on which limits the gain in efficiency. In this paper a fully soft switched two quadrant bidirectional soft switching converter for ultra capacitor interface circuits is introduced without any of the above mentioned disadvantages. This paper is organized as follows. In the second section, a description and the operation of the circuit are discussed. The design of the converter is presented in section three. In section four the simulation and experimental results are shown. Conclusions drawn from this study are presented in the last section.

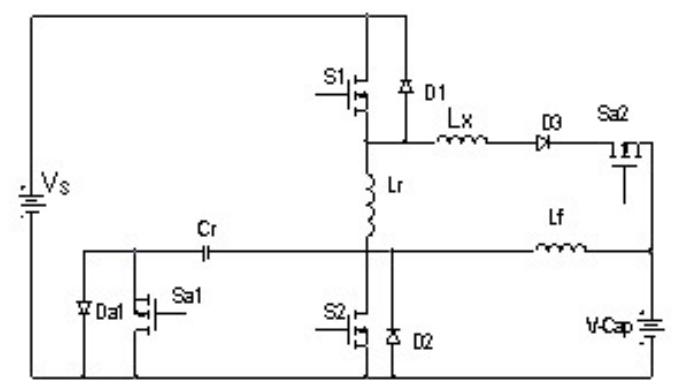

Fig. 2. The proposed bidirectional converter.

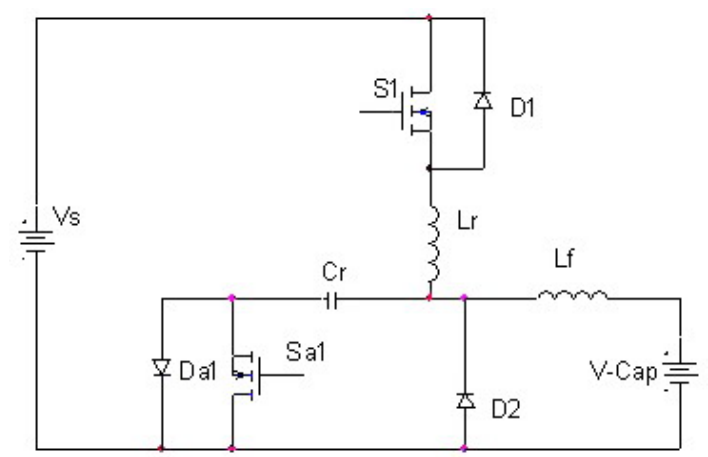

Fig. 3. The proposed converter in Buck operation.

\section{Description And Operating Principle of the CIRCUIT}

A diagram of the proposed converter is presented in Fig. 2. This converter operates in two modes of operation: (1) it acts as a ZCT Buck to charge an ultra capacitor (2) it acts as a ZVT boost to discharge an ultra capacitor. During the Boost mode, $S_{2}$ and $D_{1}$ are on while during the Buck operation mode, $S_{1}$ and $D_{2}$ are on. In addition, the converter is comprised of two auxiliary switches $\left(\mathrm{S}_{\mathrm{a} 1}, \mathrm{~S}_{\mathrm{a} 2}\right)$, a resonant inductor $\left(\mathrm{L}_{\mathrm{r}}\right)$, an auxiliary inductor $\left(\mathrm{L}_{\mathrm{x}}\right)$ and a resonant capacitor $\left(\mathrm{C}_{\mathrm{r}}\right)$.

\section{A. Principle of Operation During Buck}

The proposed converter in Buck operation is shown in Fig. 3. The main theoretical waveforms for this converter are shown in Fig. 4. It is assumed that the input voltage and the inductor $\mathrm{L}_{\mathrm{f}}$ current $\left(\mathrm{I}_{\mathrm{o}}\right)$ are constant during a switching cycle. In addition, all elements are considered to be ideal. During one switching cycle, the proposed converter has six operating modes as shown in Fig. 5.

Mode $1\left(t_{0}-t_{1}\right)$ : Prior to $t_{0}, \mathrm{D}_{2}$ is on and the output current flows through it. Furthermore at $t_{0}, S_{1}$ is turned on and the current through the resonant inductor increases linearly. $\mathrm{S}_{1}$ is softly turned on under ZCS by the resonant inductor $\mathrm{L}_{\mathrm{r}}$. At $t_{1}$, the resonant inductor current reaches $I_{0}$. Based on the equivalent circuit in Fig. 5(a), the duration to complete Mode 1 can be written as:

$$
t_{1}-t_{0}=\frac{L_{r} \cdot I_{o}}{V_{s}}
$$

The resonant $i_{L r}$ can be described as:

$$
i_{L r}(t)=\frac{V_{s}}{L_{r}} t
$$




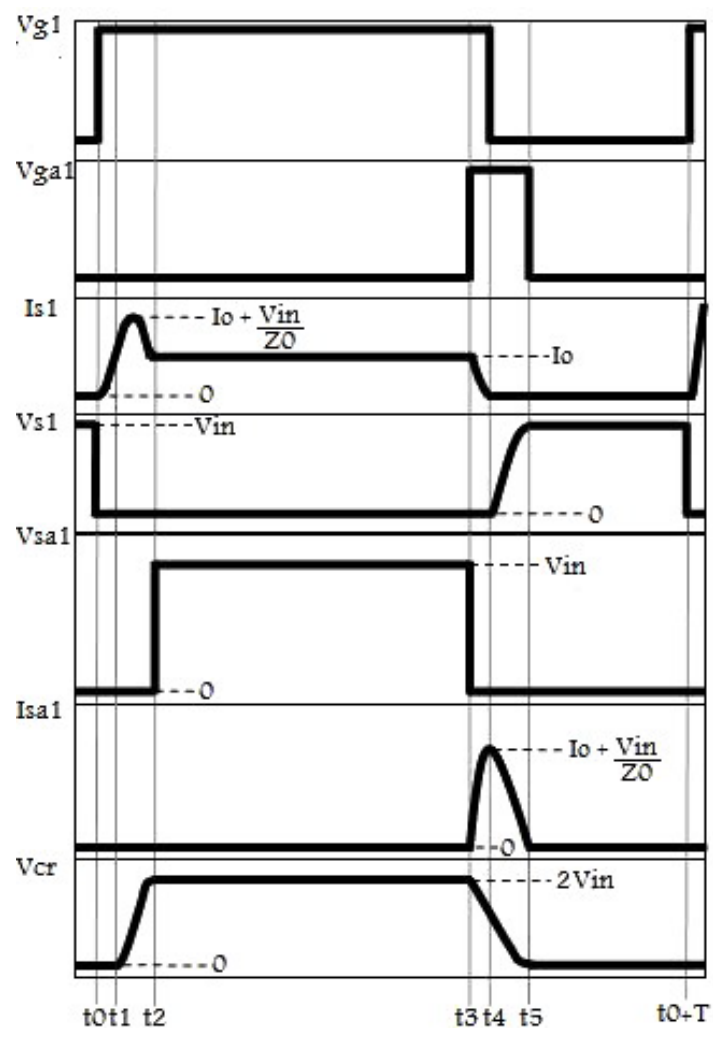

Fig. 4. The key theoretical waveforms in Buck operation.

Mode $2\left(t_{1}-t_{2}\right)$ : At $\mathrm{t} 1$, the main diode current reaches zero and $\mathrm{D}_{2}$ is softly turned off under ZCZVS and then the resonance between the resonant inductor $\left(\mathrm{L}_{\mathrm{r}}\right)$ and the resonant capacitor $\left(C_{r}\right)$ starts through $S_{1}$ and $D_{a 1}$. Based on the equivalent circuit in Fig. $5 b$, the resonant $\mathrm{i}_{\mathrm{Lr}}, \mathrm{v}_{\mathrm{Cr}}$ and $\mathrm{i}_{\mathrm{Cr}}$ can be respectively described as:

$$
\begin{gathered}
i_{L r}(t)=I_{o}+\frac{V_{s}}{Z_{0}} \sin \left(\omega_{0}\left(t-t_{1}\right)\right) \\
v_{C r}(t)=V_{s}\left(1-\cos \left(\omega_{0}\left(t-t_{1}\right)\right)\right. \\
i_{C r}(t)=\frac{V_{s}}{Z_{0}} \sin \left(\omega_{0}\left(t-t_{1}\right)\right)
\end{gathered}
$$

Where,

$$
\omega_{0}=\frac{1}{\sqrt{L_{r} C_{r}}}
$$

And,

$$
Z_{0}=\sqrt{\frac{L_{r}}{C_{r}}}
$$

Mode 3 (t2-t3): At $t_{2}$, the resonant capacitor current reaches zero and then the resonance between the resonant inductor and the resonant capacitor stops because the auxiliary switch $\left(S_{a 1}\right)$ is turned off. In this period the resonant capacitor voltage reaches $2 V_{s}$, the resonant inductor current reaches $I_{0}$ and the power flows from the input source to the ultra capacitor, as can be seen in Fig. 5(c).

Mode $4\left(t_{3}-t_{4}\right)$ : At $t_{3}$, the auxiliary switch $\left(\mathrm{S}_{\mathrm{a} 1}\right)$ is softly turned on under ZCS and the resonance between the resonant inductor and the resonant capacitor starts so that the resonant capacitor discharges. In this mode the resonant inductor current reaches zero so we can softly turned off $S_{1}$ under ZCS. (a)

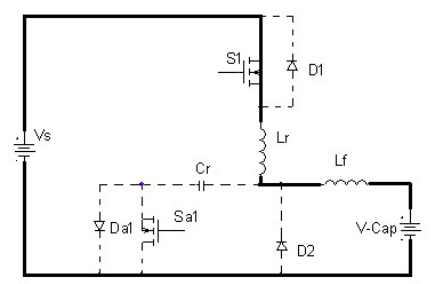

(c)

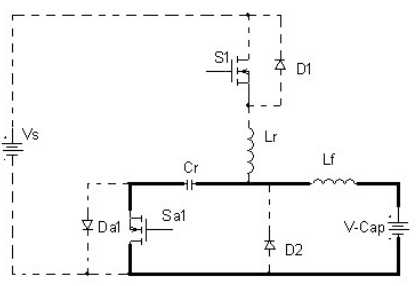

(e)

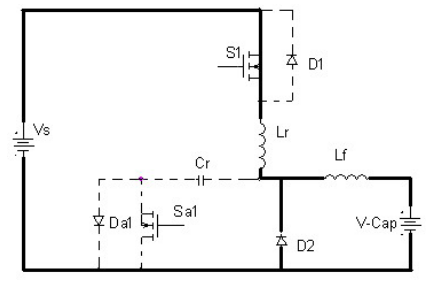

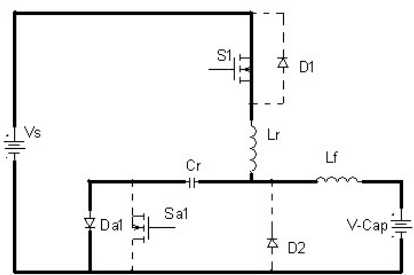

(b)

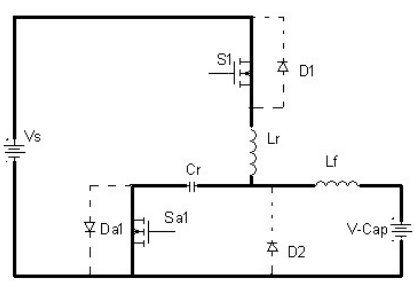

(d)

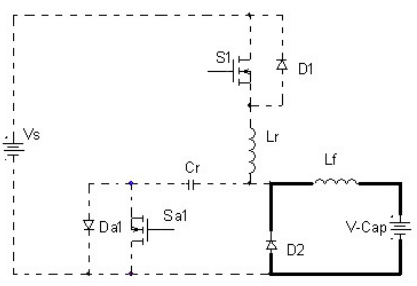

(f)
Fig. 5. Operating modes stages during Buck operation.

Based on the equivalent circuit in Fig. 5(d), the resonant $i_{\text {Lr }}$ and $\mathrm{v}_{\mathrm{Cr}}$ can be respectively described as:

$$
\begin{gathered}
i_{L r}(t)=I_{o}-\frac{V_{s}}{Z_{0}} \sin \left(\omega_{0}\left(t-t_{3}\right)\right) \\
v_{C r}(t)=V_{s}\left(1+\cos \left(\omega_{0}\left(t-t_{3}\right)\right) .\right.
\end{gathered}
$$

ZCS occurs for $S_{1}$ when the resonant inductor current reaches zero. Therefore, the constraint to achieve ZCS for $\mathrm{S}_{1}$ is determined by the following inequality:

$$
\frac{V_{s}}{Z_{0}} \geq \bar{I}_{0} .
$$

If $\frac{V_{s}}{Z_{0}}>\bar{I}_{o}$, the body diode of the main switch conducts and one more mode is added to the 6 modes.

Mode $5\left(t_{4}-t_{5}\right)$ : At $t_{4}$, the resonant inductor current reaches zero and the output inductor current flows through the resonant capacitor so that the resonant capacitor voltage decreases linearly. At the end of this mode the resonant capacitor voltage reaches zero, as shown in Fig.5(e).

Mode $6\left(t_{5}-t_{6}\right)$ : At $t_{5}$, the resonant capacitor voltage reaches zero so $\mathrm{D}_{2}$ is turned on under the ZVS condition and we can turn off the auxiliary switch $\left(S_{a 1}\right)$ under the ZVS condition as well. In this mode the energy flows from $\mathrm{L}_{\mathrm{f}}$ to the ultra capacitor, as can be seen in Fig. 5(f).

\section{B. Principle of Operation During Boost}

In order to analyze the converter during the Boost operation, the circuit is shown in Fig. 6. The main theoretical waveforms are shown in Fig. 7. It is assumed that the input voltage and 


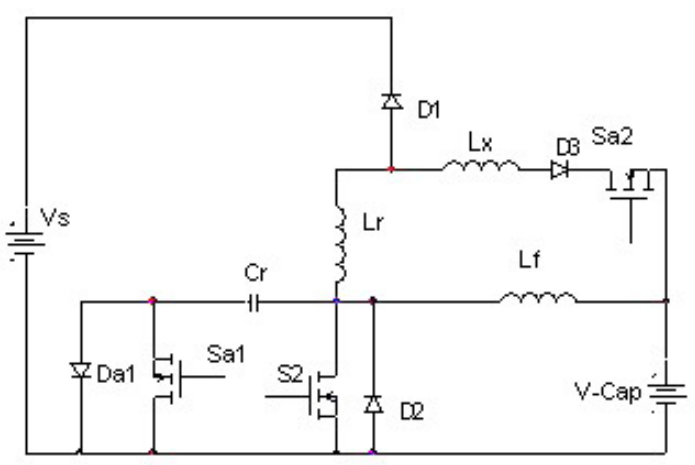

Fig. 6. The proposed converter in Boost operation.

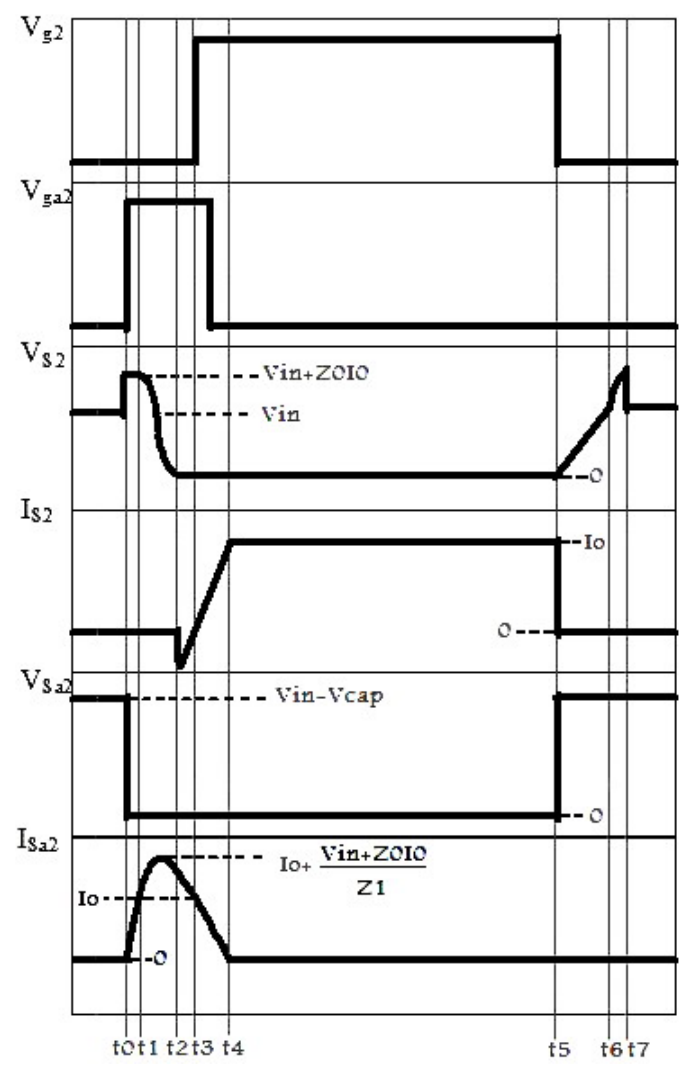

Fig. 7. Theoretical waveforms during Boost operation.

the inductor $\mathrm{L}_{\mathrm{f}}$ current $\left(\mathrm{I}_{\mathrm{o}}\right)$ are constant during a switching cycle. In addition, all elements are considered to be ideal. During one switching cycle, the proposed converter has eight operating stages in Boost mode as shown in Fig. 8.

Mode $1\left(t_{0}-t_{1}\right)$ : Prior to $t_{0}, \mathrm{D}_{1}$ is turned on, so that the energy from the ultra capacitor and the inductor $\mathrm{L}_{\mathrm{f}}$ flows to the $\mathrm{dc}$ link. At $t_{0}, \mathrm{~S}_{\mathrm{a} 1}$ and $\mathrm{S}_{\mathrm{a} 2}$ are turned on, so that the auxiliary inductor $\left(\mathrm{L}_{\mathrm{x}}\right)$ voltage is $\mathrm{V}_{\mathrm{s}}-\mathrm{V}_{\text {cap }}$ and causes the auxiliary inductor current to increase linearly. At $t_{1}, \mathrm{i}_{\mathrm{Lx}}$ reaches $\mathrm{I}_{\mathrm{o}}$. Based on the equivalent circuit in Fig. 8a, the duration of Mode 1 and $\mathrm{i}_{\mathrm{Lx}}$ can be respectively described as:

$$
\begin{aligned}
& t_{1}-t_{0}=\frac{L_{x} . I_{o}}{V_{c a p}-V_{s}} \\
& i_{L x}(t)=\frac{V_{c a p}-V_{s}}{L_{x}} t .
\end{aligned}
$$

Mode $2\left(t_{1}-t_{2}\right)$ : At $t_{1}$, $\mathrm{i}_{\mathrm{Lx}}$ reaches Io and the resonant capacitor voltage is $\mathrm{V}_{\mathrm{s}}+\mathrm{Z}_{0} \mathrm{I}_{0}$. Therefore, the resonance between the resonant capacitor $\left(C_{r}\right), L_{x}$ and $L_{r}$ starts through $S_{a 1}$ and $S_{a 2}$. At $t_{2}$, the resonant capacitor voltage reaches zero. Because of the resonance between $C_{r}, L_{x}$ and $L_{r}$, two auxiliary switches are turned on under ZCS. Based on the equivalent circuit in Fig. 8b, the resonant $\mathrm{i}_{\mathrm{Lr}}$ and $\mathrm{v}_{\mathrm{Cr}}$ can be respectively described as:

$$
\begin{array}{r}
i_{L r}(t)=\frac{V_{s}+Z_{o} I_{o}-V_{c a p}}{Z_{1}} \sin \left(\omega_{1}\left(t-t_{1}\right)\right)+I_{0} \\
v_{C r}(t)=\left(V_{s}+Z_{0} I_{0}-V_{c a p}\right) \cos \left(\omega_{1}\left(t-t_{1}\right)\right)+V_{c a p}
\end{array}
$$

where:

$$
\begin{gathered}
\omega_{1}=\frac{1}{\sqrt{C_{r}\left(L_{r}+L_{x}\right)}} \\
Z_{1}=\sqrt{\frac{L_{r}+L_{x}}{C_{r}}} .
\end{gathered}
$$

$\mathrm{C}_{\mathrm{r}}$ completely discharges in the resonance cycle by the following inequality:

$$
\begin{gathered}
V_{s}+Z_{o} \underline{I}_{o} \geq 2 V_{\text {cap }} \\
Z_{o}=\sqrt{\frac{L_{r}}{C_{r}}} .
\end{gathered}
$$

Mode 3 (t2-t3): If $V_{s}+Z_{o} \underline{I}_{o} \geq 2 V_{c a p}$, the resonant capacitor voltage becomes negative during the resonance cycle. Therefore, $\mathrm{D}_{2}$ conducts and the resonant inductor $(\mathrm{Lr})$ current decreases and reaches Io. Finally, $\mathrm{S}_{2}$ is turned on under ZCS. Based on the equivalent circuit in Fig. 8c, the resonant $i_{\text {Lr }}$ can be described as:

$$
\begin{aligned}
i_{L r}(t) & =\frac{V_{s}+Z_{0} I_{0}-V_{c a p}}{Z_{1}} \sqrt{1-\left(\frac{V_{c a p}}{V_{s}+Z_{0} I_{0}-V_{c a p}}\right)^{2}} \\
& -\frac{V_{c a p}}{L_{r}+L_{x}}\left(t-t_{2}\right)+I_{o} .
\end{aligned}
$$

Mode $4\left(t_{3}-t_{4}\right)$ : In this mode, the resonant inductor $\left(\mathrm{L}_{\mathrm{r}}\right)$ current decreases linearly from $\mathrm{I}_{0}$ and $\mathrm{i}_{\mathrm{S} 2}$ increases linearly. At $t_{4}$, $i_{S 2}$ reaches $I_{0}$ and $i_{L r}$ reaches zero. Based on the equivalent circuit in Fig. 8(d), the duration of Mode 4 and the resonant $i_{\text {Lr }}$ can be respectively described as:

$$
\begin{gathered}
\left(t_{4}-t_{3}\right)=\frac{I_{o}\left(L_{r}+L_{x}\right)}{V_{\text {cap }}} \\
i_{L r}(t)=I_{o}-\frac{V_{\text {cap }}}{L_{r}+L_{x}}\left(t-t_{3}\right) .
\end{gathered}
$$

Mode $5\left(t_{4}-t_{5}\right)$ : In this mode, the energy flows from the ultra capacitor to $\mathrm{L}_{\mathrm{f}}$ and we can turn off the auxiliary switches. The duration of this mode is determined by Fig. 8(e).

Mode $6\left(t_{5}-t_{6}\right)$ : When $\mathrm{S}_{2}$ is turned off, the inductor current flows through the resonant capacitor. In this state, the resonant capacitor charged with a constant current and its voltages reaches $V_{S}$. Therefore, $S_{2}$ is turned off under ZVS. Based on the equivalent circuit in Fig. 8(f), the duration of Mode 6 and the resonant $\mathrm{v}_{\mathrm{Cr}}$ can be respectively described as:

$$
t_{6}-t_{5}=\frac{V_{s} C_{r}}{I_{o}}
$$




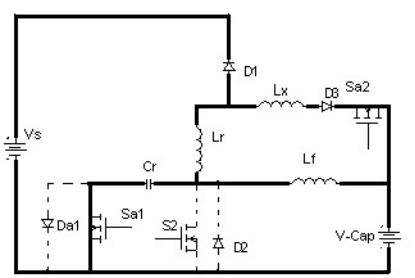

(a)

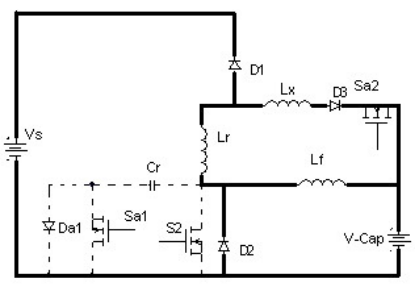

(c)

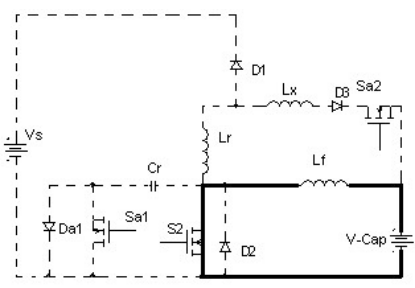

(e)

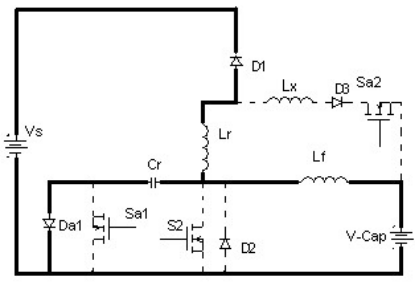

(g)

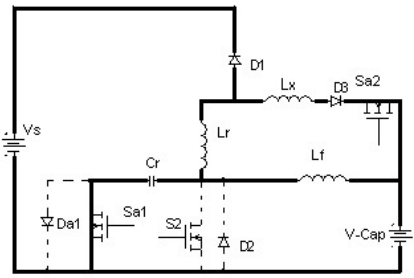

(b)

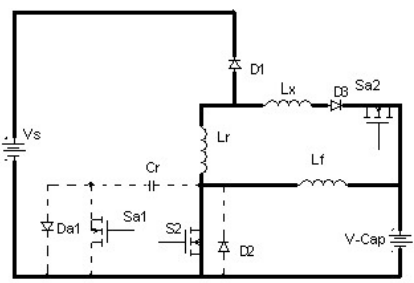

(d)

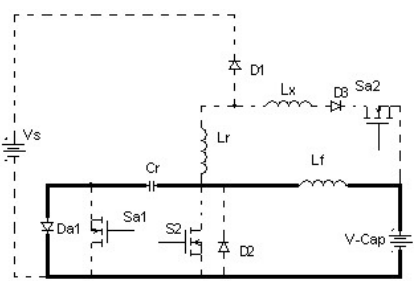

(f)

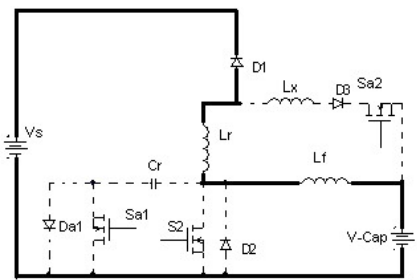

(h)
Fig. 8. Operating modes during Boost operation.

$$
v_{C r}(t)=\frac{I_{o}}{C_{r}}\left(t-t_{5}\right) .
$$

Mode $7\left(t_{6}-t_{7}\right)$ : When the resonant capacitor voltage reaches $\mathrm{V}_{\mathrm{s}}, \mathrm{D}_{1}$ starts to conduct. The diode current increases slowly by the resonant inductor, so that when the resonant inductor current reaches $I_{0}$, the resonant capacitor is charged to $V_{S}+$ $\mathrm{Z}_{0} \mathrm{I}_{0}$, as can be seen in Fig. $8(\mathrm{~g})$.

Mode $8\left(t_{7}-t_{8}\right)$ : In this mode, the resonant capacitor is overcharged and the body diode of the auxiliary switch $\left(\mathrm{S}_{\mathrm{a} 1}\right)$ is turned off under ZCS. In addition, the resonant inductor current reaches $I_{0}$ and the energy flows from the ultra capacitor, as shown in Fig. 8(h).

\section{CONVERTER Design}

In this section, a design procedure to determine the component values of the proposed bidirectional Buck-Boost converter is given. The initial conditions of the proposed converter system are given as follows.

\footnotetext{
- Battery voltage: $\quad \mathrm{V}_{\mathrm{S}}=48 \mathrm{~V}$.

- Ultra capacitor voltage: $\quad \mathrm{V}_{\text {cap }}=24 \mathrm{~V}$.
}

$\begin{array}{ll}\text { - Output Buck current: } & \mathrm{I}_{\mathrm{oBuck}}=4.2 \mathrm{~A} . \\ \text { - Output Boost current: } & \mathrm{I}_{\mathrm{oBoost}}=2 \mathrm{~A} . \\ \text { - Switching frequency: } & \mathrm{f}_{\mathrm{S}}=100 \mathrm{kHz} .\end{array}$

\section{A. Resonant Capacitor and Inductor}

ZCS occurs for $S_{1}$ when the resonant inductor current reaches zero. Therefore, the constraint to achieve ZCS for $S_{1}$ is determined by the following inequality:

$$
\frac{V_{s}}{Z_{0}} \geq \bar{I}_{\text {obuck }} .
$$

After that, in Boost operation, $\mathrm{C}_{\mathrm{r}}$ completely discharges in the resonance cycle by the following inequality:

$$
\begin{gathered}
V_{s}+Z_{o} \underline{I}_{o b o o s t} \geq 2 V_{c a p} \\
Z_{o}=\sqrt{\frac{L_{r}}{C_{r}}} .
\end{gathered}
$$

If $V_{s} \leq 2 V_{\text {cap }}$, the best operation for the proposed converter can be calculated by using (24) and (25), i.e.

$$
\frac{2 V_{\text {cap }}-V_{s}}{\underline{I}_{\text {oboost }}} \leq Z_{o} \leq \frac{V_{s}}{\bar{I}_{\text {obuck }}} \text {. }
$$

If $V_{s} \geq 2 V_{\text {cap }}$, the best operation for the proposed converter can be calculated by using (24). $\mathrm{C}_{\mathrm{r}}$ and $\mathrm{L}_{\mathrm{x}}$ can be respectively calculated by the main switch and the auxiliary switch speed.

With the values of the battery voltage and the output Buck current by the initial conditions, equation (24) is able to define the characteristic impedance.

$$
\mathrm{Z}_{0}=\mathrm{V}_{\mathrm{S}} / \overline{\mathrm{I}}_{\mathrm{oBuck}}=48 / 4.2=11.43
$$

In designing methods, the coefficient for safety is usually $20 \%$.

$$
\mathrm{Z}_{0}(\text { design })=0.8 \mathrm{Z}_{0} \text { (theory) }=0.8 \times 11.43=9.14
$$

With the value of the characteristic impedance, equation (26) is able to define the resonant inductor and the capacitor. By Choosing $\mathrm{C}_{\mathrm{r}}=5 \mathrm{nF}$, the resonant inductor is given by:

$$
\mathrm{L}_{\mathrm{r}}=\mathrm{Z}_{0^{2}} \times \mathrm{C}_{\mathrm{r}}=0.42 \mu \mathrm{H}
$$

However, the value of the resonant inductor is not sufficient to achieve soft switching in Buck operation. By increasing the value of the resonant inductor and choosing $\mathrm{L}_{\mathrm{r}}=1.5 \mu \mathrm{H}$, the resonant capacitor is given by:

$$
\mathrm{C}_{\mathrm{r}}=\mathrm{L}_{\mathrm{r}} / \mathrm{Z}_{0^{2}}=18 \mathrm{nF}
$$

\section{B. Duty Cycle in Buck and Boost Operation}

In Buck operation the maximum duty cycle $(\bar{D})$ is not limited. However, turning off the main switch is not allowed before the charging of the resonant capacitor, so the minimum duty cycle $(\underline{D})$ is limited.

Based on Fig.9, $\underline{D}$ is determined by the following inequality:

$$
\underline{D} T>T_{m} .
$$

In Boost operation $\underline{D}$ is not limited. However, before the main switch is turned on again, the resonant capacitor should be discharged, so $\bar{D}$ is limited.

Based on Fig.10 $\bar{D}$ is determined by the following inequality:

$$
\bar{D} T<T-T_{n} .
$$




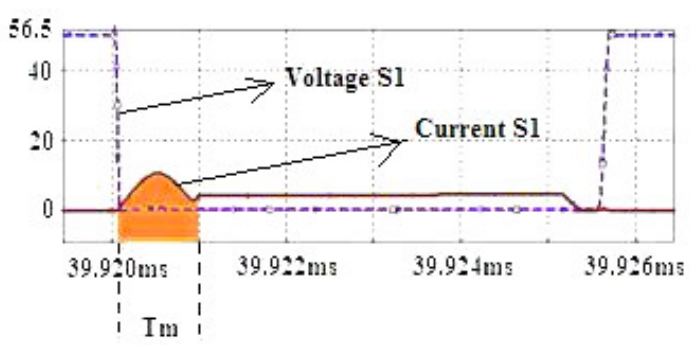

Fig. 9. The voltage and current of main switch in Buck operation.

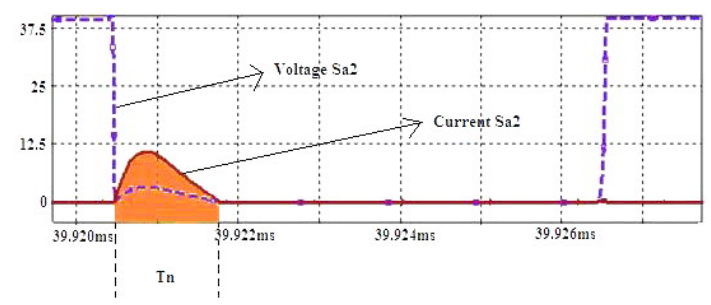

Fig. 10. The voltage and current of auxiliary switch $\left(\mathrm{S}_{\mathrm{a} 2}\right)$ in Boost operation.

\section{Ultra capacitor voltage}

The voltage of the ultra capacitor is very important. The ultra capacitor and the converter can be damaged seriously if; the ultra capacitor voltage is higher than the allowable maximum or lower than the allowable minimum.

The ultra capacitor is charged during Buck operation so:

$$
\bar{V}_{c a p}=V_{s}
$$

where $\bar{V}_{\text {cap }}$ is the maximum ultra capacitor voltage and $\mathrm{V}_{\mathrm{s}}$ is the battery voltage.

However, the ultra capacitor minimum voltage is determined by the following equation:

$$
\underline{V}_{c a p}=\frac{V_{s}+Z_{o} \underline{I}_{o b o o s t}}{2}
$$

where $\underline{V}_{\text {cap }}$ is the minimum ultra capacitor voltage and $\underline{I}_{o B o o s t}$ is the minimum output current of the proposed converter in Boost mode.

\section{Simulation AND EXPERIMENTAL RESUlts}

To verify the above analysis, a simulation model of the proposed ZCT Buck converter has been built in Orcad. The parameters are shown in table 1. The model is shown in Fig.11.

The simulation results are shown in Fig.12 and the experimental results are shown in Fig.13.

TABLE I

THE PARAMETERS OF COMPONENTS

\begin{tabular}{|l|l|}
\hline component & parameter \\
\hline Input voltage & $48 \mathrm{~V}$ \\
\hline Output voltage & $24 \mathrm{~V}$ \\
\hline Switching frequency & $100 \mathrm{kHz}$ \\
\hline Output current & $4.2 \mathrm{~A}$ \\
\hline Filter inductor & $200 \mu \mathrm{H}$ \\
\hline Filter capacitor & $100 \mu \mathrm{F}$ \\
\hline Switches & $\mathrm{IRF} 540$ \\
\hline Resonant inductor & $1.5 \mu \mathrm{H}$ \\
\hline Resonant capacitor & $18 \mathrm{nF}$ \\
\hline
\end{tabular}

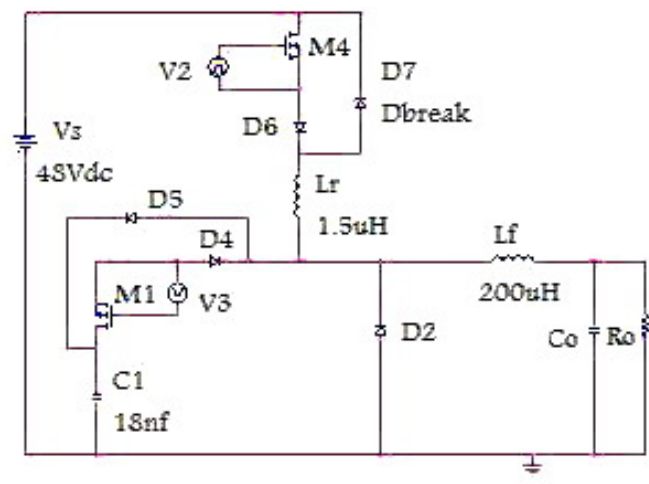

Fig. 11. Simulation model of the ZCT Buck converter.

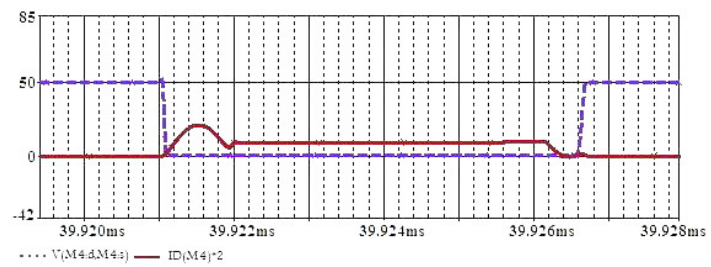

(a)

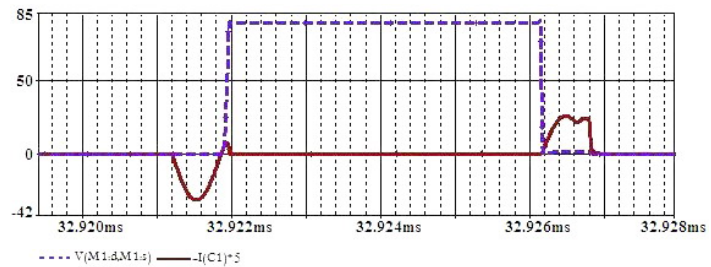

(b)

Fig. 12. Simulation results for the proposed ZCT Buck converter. (a) The voltage and current of main switch $\left(\mathrm{S}_{1}\right)$. (b) The voltage and current of auxiliary switch $\left(\mathrm{S}_{\mathrm{a} 1}\right)$.

Fig.12. shows that soft switching is applied in the main switch $\left(\mathrm{S}_{1}\right)$ and the auxiliary switch $\left(\mathrm{S}_{\mathrm{a} 1}\right)$ and Fig.13 shows that the experimental waveforms resemble the simulation waveforms, which confirms the theoretical and simulation results.

The efficiency curves for the proposed ZCT Buck converter and a conventional Buck converter are shown in Fig.14. The nominal power of the proposed ZCT Buck converter is 100 Watts so; at this power the efficiency is maximized. However, when the power is less than the nominal power (because the losses of the auxiliary circuit are increased to higher than the main circuit) the efficiency is decreased. This is common for all soft switching converters. Fig.14 shows that the efficiency of the proposed ZCT Buck converter at nominal power is higher than $96 \%$.

To verify the above analysis, a simulation model of the proposed ZVT Boost converter was built in Orcad. The parameters are shown in table II, and the model is shown in Fig.15.

The simulation results are shown in Fig.16 and the experimental results are shown in Fig.17.

Fig.16. shows that soft switching is applied in the main switch $\left(S_{2}\right)$ and the auxiliary switch $\left(S_{\mathrm{a} 2}\right)$ and Fig.17 shows that the experimental waveforms resemble the simulation waveforms, which confirms the theoretical and simulation 


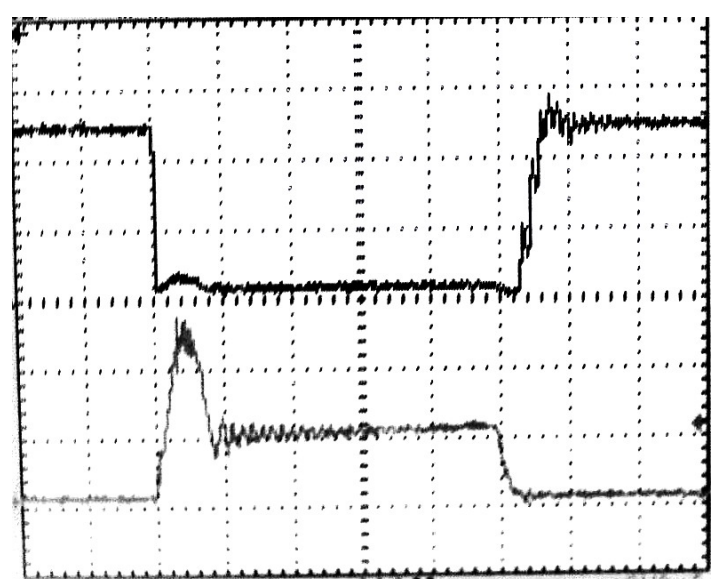

(a)

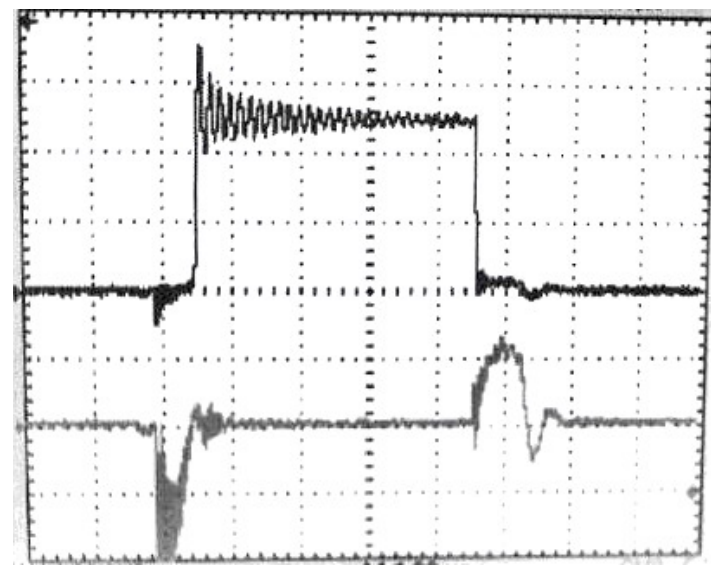

(b)

Fig. 13. Experimental results for the proposed ZCT Buck converter. (a) The voltage and current of main switch. (b) The voltage and current of auxiliary switch.

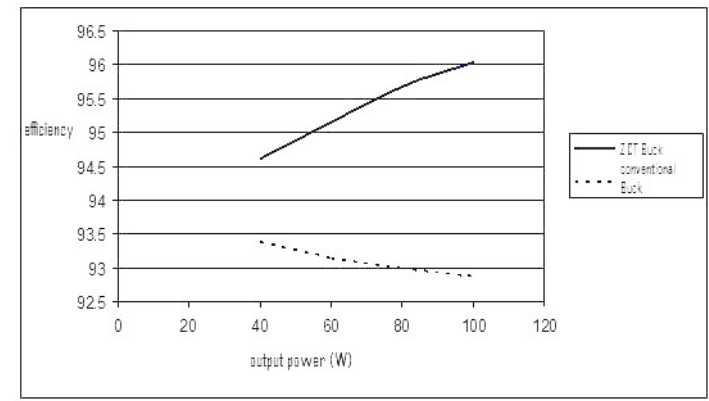

Fig. 14. Efficiency curves.

TABLE II

THE PARAMETERS OF COMPONENTS

\begin{tabular}{|l|l|}
\hline component & parameter \\
\hline Input voltage & $24 \mathrm{~V}$ \\
\hline Output voltage & $48 \mathrm{~V}$ \\
\hline Switching frequency & $100 \mathrm{kHz}$ \\
\hline Output current & $2 \mathrm{~A}$ \\
\hline Filter inductor & $200 \mu \mathrm{H}$ \\
\hline Filter capacitor & $100 \mu \mathrm{F}$ \\
\hline Switches & IRF540 \\
\hline Resonant inductor & $1.5 \mu \mathrm{H}$ \\
\hline Resonant capacitor & $18 \mathrm{nF}$ \\
\hline Auxiliary inductor & $1 \mu \mathrm{H}$ \\
\hline
\end{tabular}

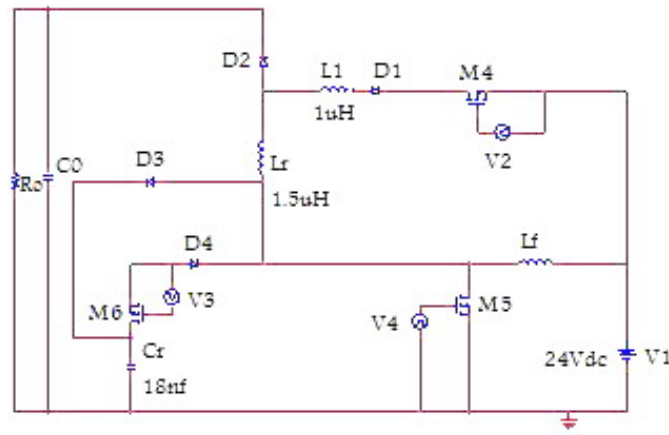

Fig. 15. Simulation model of the ZVT Boost converter.

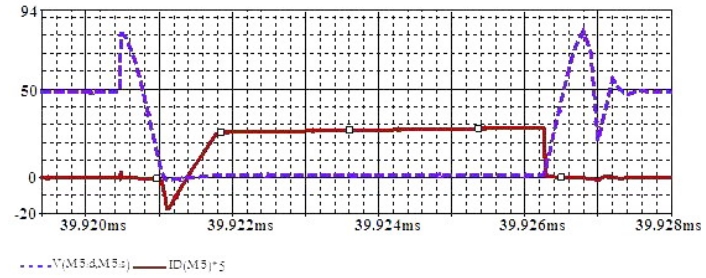

(a)

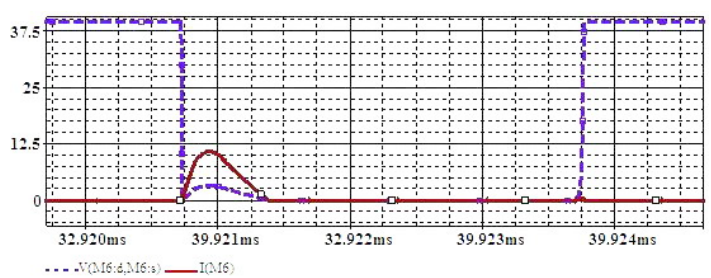

(b)

Fig. 16. Simulation results for the proposed ZVT Boost converter. (a) The voltage and current of main switch $\left(S_{2}\right)$. (b) The voltage and current of auxiliary switch $\left(\mathrm{S}_{\mathrm{a} 2}\right)$.

results.

The efficiency curves for the proposed ZVT Boost converter and a conventional Boost converter are shown in Fig.18. The nominal power of the proposed ZVT Boost converter is 100 Watts so; at this power the efficiency is maximized. However, when the power is less than the nominal power (because the losses of the auxiliary circuit are increased to higher than the main circuit) the efficiency is decreased. This is common for all soft switching converters. Fig.18 shows that the efficiency of the proposed ZVT Boost converter at nominal power is higher than $95 \%$.

\section{CONCLUSION}

This paper describes a two quadrant bidirectional soft switching converter for ultra capacitor interface circuits. For the interface circuit, ZVT and ZCT techniques are applied that guarantee the soft switching condition for all semiconductor devices. The proposed converter acts as a ZCT Buck to charge an ultra capacitor. On the other hand, it acts as a ZVT Boost to discharge an ultra capacitor. The proposed converter has the advantages of high efficiency, a simple circuit, low cost and reduced weight. On top of that, it uses limited elements to achieve soft switching in comparison with other articles. The measured efficiency of the proposed converter in Buck mode is more than $96 \%$ and in Boost mode it is more than 


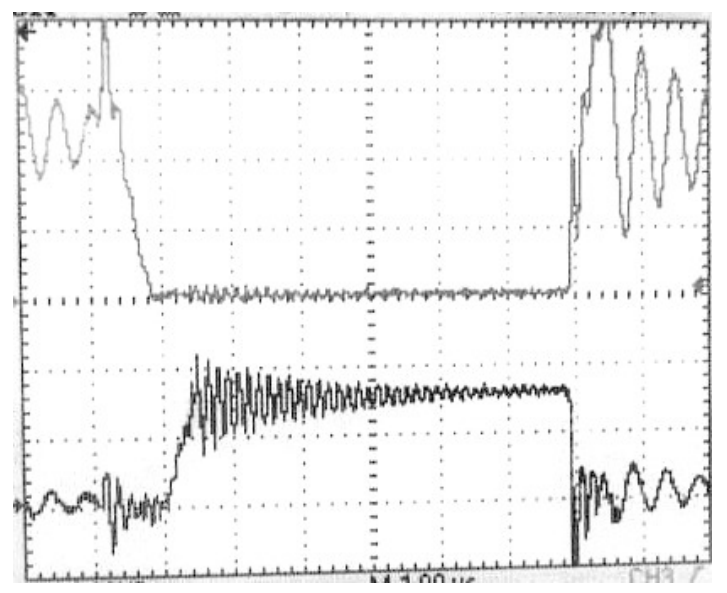

(a)

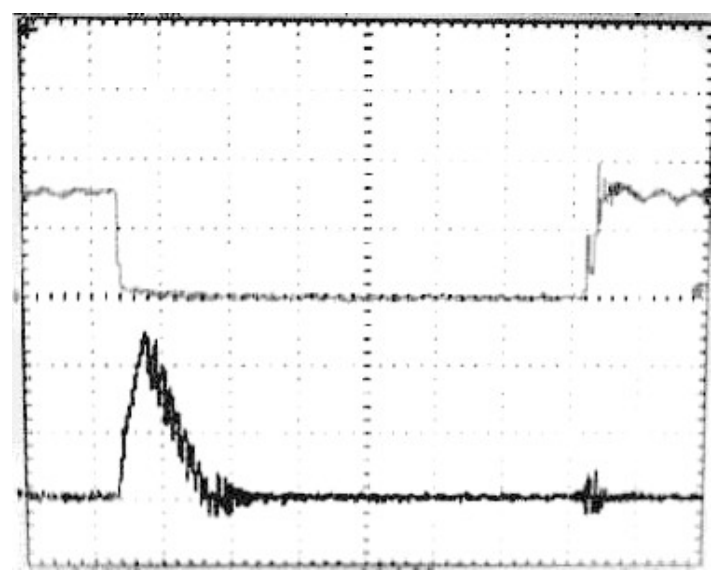

(b)

Fig. 17. Experimental results for the proposed ZVT Boost converter. (a) The voltage and current of main switch $\left(\mathrm{S}_{2}\right)$. (b) The voltage and current of auxiliary switch $\left(\mathrm{S}_{\mathrm{a} 2}\right)$.

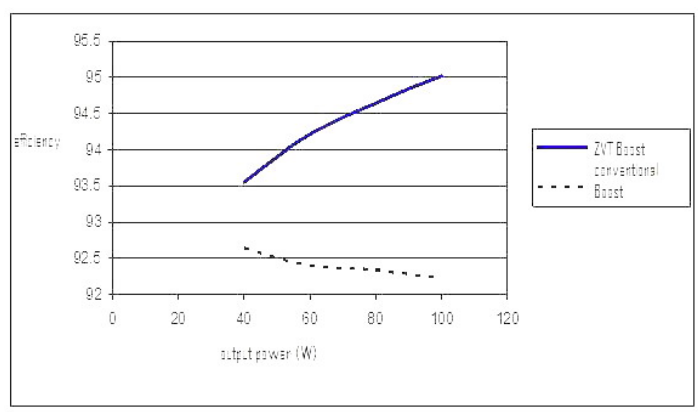

Fig. 18. Efficiency curves.

95\% under full load. In case of a light load, the efficiency decreases due to the fact that the circulating energy involved in the resonant process is constant and independent of the load. The soft switching condition is achieved for the full load range. A comparison between of the proposed converter for ultra capacitor interface circuits and other interface circuits demonstrates its superior performance.

A laboratory prototype converter was designed and realized for hybrid vehicle applications. The experimental results presented, confirm the theoretical and simulation results.

\section{REFERENCES}

[1] S. K. Biradar, R. A. Patil, and M. Ullegaddi, "Energy storage system in electric vehicle," in Proc. IEEE Power Quality Conf., pp. 247-255, 1998.

[2] X. Yan and D. Patterson, "Improvement of driving range, acceleration and deceleration performances in an electric vehicle propulsion system," in Proc. IEEE Power Electronics Specialists Conf., pp. 638-643, Jun. 1999.

[3] L. Lianbing, L. Sun, Z. Liu, and H. Sun, "Ultra-capacitor control strategy of EV with energy hybridization," in Proc. IEEE Vehicle Power and Propulsion Conf., pp. 1-4, Sep. 2008.

[4] P. Barrade, A. Rufe, "Current Capability and Power Density of Supercapacitors," EPE-Toulouse, 2003.

[5] M.Y.Ayad, S.Rael, "Hybrid Power Source using Supercapacitors and Battery," EPE-Toulouse, 2003.

[6] F. Caricchi, F. Crescimbini, F. G. Capponi, and L. Solero, "Study of bidirectional Buck-Boost converter topologies for application in electrical vehicle motor drives," in Proc. IEEE APEC, Vol. 1, pp. 287-293, Feb. 1998.

[7] J.W.Dixon, M.E.Ortuza, "Ultracapacitors +DC -DC Converters in Regenerative Braking System,” IEEE AESS System Magazine, pp 16-21. August 2002.

[8] Guichao, H. and Ching, S. L. and Yimin, J. and Lee, F. C. Y., "Novel zero-voltage-transition pwm converters," IEEE Transactions on Power Electronics. Vol. 9. No. 2. pp. 213-219, Mar. 1994.

[9] Hua, G. and Yang, E. X. and Jiang, Y. and Lee, F. C., "Novel zerocurrent-transition pwm converters," IEEE Power Electronics Specialists Conference, pp. 538-544, 1993.

[10] Mar, M. and Schroder, D., "A novel zero-current-transition full bridge DC-DC converter," IEEE Power Electronics Specialists Conference, Vol. 1. pp. 664-669, 1996.

[11] C. M. de Oliveira Stein and H. L. Hey, "A true ZCZVT Commutation Cell for PWM Converter," IEEE Trans. Power Electron, Vol. 15, No. 1, pp. 185-193, Jan. 2000.

[12] M. L. Martins, J. L. Russi, J. R. Pinheiro, H. A. Grundling, and H. L. Hey, "Unified design for ZVT PWM converters with resonant auxiliary circuit," Proc. IEE-Electr. Power Appl, Vol. 151, No. 3, pp. 303-312, Mar. 2004.

[13] P. J. M. Menegaz, J. L. F. Vieira, and D. S. L. Simonetti, "A ZVT DCDC self resonant boost converter with improved features," in Proc. IEEE Power Electronics Specialists Conf. (PESC), pp. 1631-1654, 2004.

[14] K. S. Ma, J. D. Lee, and Y. M. Kim, "New ZVS-PWM converters with zero-current-switched auxiliary switch for low power applications," in Proc. IEEE Power Electronics Specialists Conf. (PESC), pp. 1744-1748, 2004.

[15] N. Jain, P. K. Jain, and G. Joos, “A zero voltage transition boost converter employing A soft switching auxiliary circuit with reduced conduction losses," IEEE Trans. Power Electron, Vol. 19, No. 1, pp. 130-139, Jan. 2004.

[16] Rufer, A. Ch. and Ravokatrasolofo, H., "Static converter for complementary energy storage with battery and supercapacitor," Conference Boostcap, Fribourg, pp. 1-5, 1999.

[17] Gomez, J. L. and Enjeti, P. N. and Jouanne, A. V., "An approach to achieve ride-through of an adjustable-speed drive with flyback converter modules powered by supercapacitors," IEEE Transactions on Industry Applications, Vol. 38, No. 2, pp. 514-522, Mar./Apr. 2002.

[18] Rufer, A., "Power electronic interface for a supercapacitor basedenergy storage substation in DC transportation network," EPE, Toulouse, 2003.

[19] Rufer, A. and Barrade, P. A., "Supercapacitor-based energy-storage system for elevators with soft commutated interface", IEEE Transactions on Industry Applications, Vol. 38, No. 5, pp. 1151-1159, Sep./Oct. 2002.

[20] Yamamoto, K. and Hiraki, E. and Tanaka, T. and Nakaoka, M. and Mishima, T., "Bidirectional dc-dc converter with full-bridge / pushpull circuit for automobile electric power systems," 37th IEEE Power Electronics Specialists Conference, pp. 1-5, 2006.

[21] Sung-Sae Lee, Sang-Kyoo Han, Gun-Woo Moon, "A new high efficiency half bridge converter with improved ZVS performance", Journal of Power Electronics, Vol. 6, No. 3, pp.187-194, Jul. 2006.

[22] Chong-Eun Kim, Sang-Kyoo Han, Ki-Bum Park, Gun-Woo Moon, "A new high efficiency ZVZCS bidirectional DC/DC converter for HEV $42 \mathrm{~V}$ power systems", Journal of Power Electronics, Vol. 6, No. 3, pp.271-278, Jul. 2006.

[23] Morcos, M. M. and Dillman, N. G. and Mersman, C. R., "Battery charger for electric vehicles," IEEE Power Engineering Review, Vol. 20, No. 11, pp. 8-11, 2000. 
[24] Sung-Sae Lee, Seong-Wook Choi, Gun-Woo Moon, "High efficiency active clamp forward converter with synchronous switch controlled ZVS operation," Journal of Power Electronics, Vol. 6, No. 2, pp.131-138, Apr. 2006.

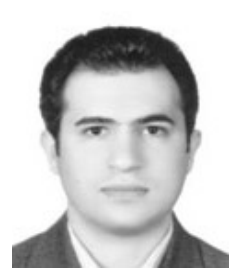

Amin Mirzaei was born in Rasht, Iran, in 1982. He received his B.S. in Electrical Engineering from the Power and Water University of Technology, Tehran, Iran, in 2005 and his M.S. in Electrical Engineering from the Isfahan University of Technology, Isfahan, Iran, in 2008. He is currently working toward his Ph.D. in Electrical Engineering at the Universiti Teknologi Malaysia, Johor Bahru, Malaysia. His current research converters. interests include soft switching techniques in $\mathrm{dc}-\mathrm{dc}$

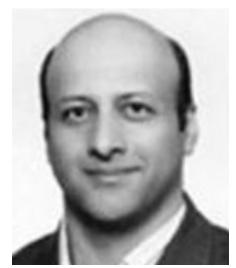

Hosein Farzanehfard was born in Isfahan, Iran, in 1961. He received his B.S. and M.S. in Electrical Engineering from the University of Missouri, Columbia, in 1983 and 1985, respectively, and his Ph.D. from Virginia Polytechnic Institute and State University, Blacksburg, in 1992. Since 1993, he has been a faculty member in the Department of Electrical and Computer Engineering, Isfahan University of Technology, Isfahan, Iran, where he is currently an Associate Professor and the President of the Information and Communication Technology Institute. His current research interests include high-frequency soft-switching converters, pulse power applications, power factor correction, active power filters, and highfrequency electronic ballasts. He is the author or coauthor of more than 70 technical papers published in journals and conference proceedings.

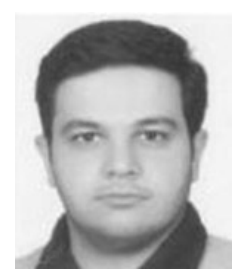

Ehsan Adib was born in Isfahan, Iran, in 1982. He received his B.S., M.S. and Ph.D. in Electrical Engineering in 2003, 2006 and 2009, respectively, from the Isfahan University of Technology, Isfahan, Iran. His current research interests include soft switching techniques in $\mathrm{dc}-\mathrm{dc}$ converters, pulse power applications and power factor correction.

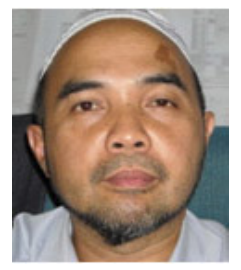

Awang Jusoh was born in Terengganu, Malaysia in 1964. He received his B.Eng. from Brighton Polytechnic, UK, in 1988 and his M.Sc. and Ph.D. from the University of Birmingham, UK in 1995 and 2004, respectively. He is currently a Senior Lecturer in the Department of Energy Conversion, Faculty of Electrical Engineering, Universiti Teknologi Malaysia, Malaysia. His current research interests are the areas of modeling, analysis and control of power electronics systems.

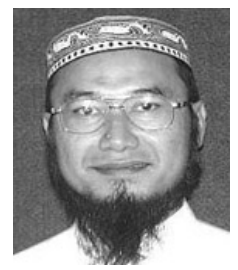

Zainal Salam obtained his B.Sc., M.E.E. and Ph.D. from the University of California, the Universiti Teknologi Malaysia (UTM) and the University of Birmingham, UK, in 1985, 1989 and 1997, respectively. He has been a lecturer at UTM for 24 years and is now a Professor of Power Electronics in the Faculty of Electrical Engineering. He has also been working on several research projects and consulting jobs on battery powered converters. Currently he is the Director of the Inverter Quality Control Center (IQCC) UTM which is responsible for testing PV inverters that are to be connected to the local utility grid. His research interests include all areas of power electronics, renewable energy, power electronics and machine control. 